\title{
NEW SYNTHESIS 1,3,4-OXADIAZOLES \\ OF AMINO ACID VIA ELECTROPHILIC ACTIVATION OF NITROALCANES IN PPA
}

\section{N.K. Kirilov, A.V. Aksenov, N.A. Aksenov and N.A. Arutyunov}

Department of Chemistry, North Caucasus Federal University, 355009, Russian Federation, Stavropol, 1a Pushkin St.

DOI: 10.19163/MedChemRussia2021-2021-512

E-mail: lycheron@gmail.com

Recently our research group has reported efficient synthesis of 1,3,4-oxadiazoles, containing different substituents in $\mathbf{2}$ and $\mathbf{5}$ positions via electrophilic activation of nitroalkanes in polyphosphoric acid and further cyclocondensation with acylhydrozides [1]. We wondered about the possibility of expanding of employing of this reaction using various amino acids (1) on the way to 1,3,4-oxadiazoles with an amino group (2) in the alpha position (Figure 1). This reaction was found to take place at $120^{\circ} \mathrm{C}$ in good yields $(50-80 \%)$.<smiles>[R]NC([R])C(=O)O</smiles>

1

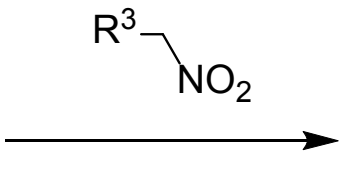

PPA $120^{\circ} \mathrm{C}, 2 \mathrm{~h}$

$\mathrm{R}^{1}, \mathrm{R}^{2}, \mathrm{R}^{3}=\mathrm{H}, \mathrm{Alk}, \mathrm{Ar}$

Fig. 1.

Thus, as a result of the study, the reaction of alpha amino acid hydrazides in a PFC medium with activated nitroalkanes under mild conditions, including cyclocondensation, was discovered.

Acknowledgements. This work was supported by Russian Foundation for Basic Research № 20-33-90026.

\section{References}

[1] Aksenov A. V., Khamraev V., Aksenov N. A. et al. RSC advances 2019, 9 (12), 6636-6642. 